\title{
Müziğin Duygu Durumu ile Yüz İfadelerinin Uyumunun 5 Yaşındaki Çocuklarda Ritim Senkronizasyonuna Olan Etkisi ${ }^{1}$
}

\section{The Effect of the Congruency of Emotional State of Music and Facial Expressions on Rhythm Synchronization in 5-Year-Old Children}

\author{
Nur İNCI ${ }^{1 *}$, Sema KARAKELLE ${ }^{2}$ \\ ${ }^{1}$ Araştırma Görevlisi, Doğuş Üniversitesi, Fen-Edebiyat Fakültesi, Psikoloji Bölümü, nurinci@yahoo.com, \\ https://orcid.org/0000-0002-2166-8515*Sorumlu Yazar \\ ${ }^{2}$ Doç. Dr., İstanbul Üniversitesi, Edebiyat Fakültesi, Psikoloji Bölümü, semakarakelle@gmail.com, \\ https://orcid.org/0000-0002-3899-6670
}

Geliş tarihi/Received : 11.04.2021 Kabul tarihi/Accepted: 23.06.2021 Yayın tarihi/Published:30.06.2021

\section{ÖZET}

Bu araştırmada amaçlanan, okul öncesi dönemindeki çocukların ritim senkronizasyonlarını gerçekleștirmelerinde, önceden seçilmiş olan müzik parçalarına ait olan duygu durumlarıyla uyumlu ve uyumsuz mimiklerin etkisini değerlendirmektir. Katılımcılar İstanbul ilinde, 60-71 aylık toplam 96 çocuğu kapsamaktadır. Çocukların ritim senkronizasyonlarını ölçmek için araştırmacı Müzikli Senkronizasyon Görevi’ni (MSG) geliştirilmiştir. Ek olarak çocukların bilişsel esnekliğinin kontrol edilmesi amacıyla Baş-Ayak Parmakları-Dizler-Omuzlar Görevi (BADO) kullanılmıştır. Sonuçlara göre ilk olarak, müzik parçalarında hissedilen duygu durumlarıyla eşleşen mimikler, çocukların ritmik olarak senkronize olmalarında daha etkilidir. Çalışmanın ikinci sonucunda ise, araştırma için seçilen duygu durumu türleri herhangi bir fark yaratmadan (mutlu ya da nötr), uyumun senkronizasyonu olumlu yönde etkilemesidir. Bu sonuçlar, diğer senkronizasyon çalışmalarına eşlik etmekte beraber, senkronizasyon ölçümünde müzik ve yüz ifadelerinin etkisine bakılması açısından da literatürde öncüldür. Bedenlenmiş bilişin alt boyutlarının (duygu, algı ve hareket) birlikte hareketinin gerçekleştiği, ortak niyete bağlı işbirlikçi faaliyetin gözlemlendiği ve mimik ile müziğe ait duygusal ipuçlarının uyumu sayesinde katılımcıların senkronize olmalarındaki hataların düşük seviyelere çekildiği bir çalışmadır.

Anahtar Kelimeler: Ritim senkronizasyonu, bedenlenmiş biliş, ortak niyet, müzikte duygu algılaması, müzik algisi.

\begin{abstract}
The aim of this study is to evaluate the effect of mimics that are congruent with the emotional states that match the pre-selected music pieces and are not compatible with the rhythm synchronization of preschool children. Participants included 96 children, 60-71 months old, in the province of Istanbul. Researcher Musical Synchronization Task (MST) has been developed to measure children's rhythm synchronization. In addition, the Heads-Toes-Knees-Shoulders Task (HTKS) was used to control the cognitive flexibility of children. According to the results, mimics that match the emotional states felt in music pieces are more effective for children to synchronize rhythmically. Secondly, the congruency affects synchronization positively, without making any difference (happy or neutral) in the mood types selected for the study. While these results accompany other synchronization studies, it also pioneers in the literature in terms of looking at the effect of music and facial expressions in synchronization measurement. The study conveys sub-dimensions of embodied cognition (emotion, perception and movement) act together, collaborative activity based on common intention is observed, and thanks to the harmony of the emotional cues of the mimic and music, the errors in the synchronization of the participants are reduced to low levels.
\end{abstract}

Keywords: Rhythm synchronization, embodied cognition, joint intention, musical emotion peception, music perception.

\footnotetext{
${ }^{1}$ Bu makale Nur İNCİ'nin 2019 yılı Haziran ayında İstanbul Üniversitesi Psikoloji Yüksek Lisans programında yazdığı tezden türetilmiştir.
} 


\section{GíRIş}

Bilim insanları, psikolojinin temelini oluşturan zihin ve beden ilişkisini incelemek ve bunun canlıların davranışlarına olan yansımalarını ortaya koymak amacıyla birtakım araştırmalar yürütmektedir. Günümüzde zihin ve beden ilişkisini irdeleyen görüşlerden birisi olan bedenlenmiş biliş (embodied cognition) kavramı, bir canlının bedeninin zihni kontrol edilmesi yerine, vücudunun kendisinin, canlıların düşünce yapısının bir unsuru olmasıyla çerçevelenmiştir (Leman ve Maes, 2014; Niendenthal, 2007; Thelen, 2000). Başka deyişle zihin, bir kontrol mekanizması olmaktan çıkıp beden ile ortaklaşa ve dinamik bir şekilde hareket eden bir yapı haline dönüşmektedir. Bunun gerçekleşmesinde beden hareketlerinin, algılama süreçlerinin ve duyguların etkisi bulunmaktadır.

İnsanlarda beden hareketleri hem mikro hem de makro seviyededir: koşmak, dans etmek, enstrüman çalmak vb. türünde makro seviyedeyken, mimikler mikro hareketlerdir. Mimikler bedenlenmiş bilişte önemli bir yere sahiptir; çünkü burada duygusal olmayan sözel ipuçları ile bireylerin duyguları somutlaşır ve algılanabilir bir hale gelir (Zhou ve Fischer, 2018). İnsanlar, yaşamlarının ilk anlarından itibaren bir yüz ifadesindeki duyguyu taklit edebilme ve mimikleri sergileme yetisine sahiptir (Wood, Rychlowska, Korb ve Niedental, 2016). Müziğin ise, tıpk1 mimikler gibi bedenlenmiş bilişi birleştirici bir güce sahip olduğu söylenebilir.

Bir müzik bestesinin bölümlerinin (melodi, ritim, vb.) algılanması ve bireylerde bıraktığı his, bir sanat eseri olması dolayısıyla kişiden kişiye değişkenlik gösterecektir; öte yandan besteler, bireylerde ortak hisler de yaratabilir. Juslin ve Slobada (2011) çalışmaları sonucunda müziğin algılanışın tek bir teoriyle açıklanmaması gerektiğini savunmuşlardır. Araştırmacılara göre, bir müzik parçası dinlediğinde, kişi onu anlamaya ve yarattığı hissi algılamaya çalışır. Kişi, müziğin onda bıraktığ 1 duyguları belli bir sisteme dahil eder ve ona göre hareket eder. Müziğin anlaşılması sayesinde bireyler ritme uyum sağlar ve müzikle birlikte senkronik hareketler geliştirir.

Canlılar içerisinde insanlar, doğdukları andan itibaren hem basit hem de karmaşık ritim farklılıklarını ayırt edebilecek özelliklere sahip olan ender varlıklardır. Ayrıca ritim farklılıklarına göre hareket etmeyi ve senkronize davranışlar geliştirmeyi de yine küçük yaşlardan itibaren yapabilirler (Tomasello, 2008). Örneğin, bir bebek daha hayatının ilk döneminde dinlediği bir müzik parçasına el çırpma, mırıldanma, baş sallama gibi tepkiler gösterir. Sacks (2008) kitabında yazdığı anısıyla müziğin ve müzikle senkronize olmanın hayatını kurtardığından bahseder. Hem kaygı düzeyini kontrol etmeyi hem de motor ve işitsel becerilerini uyumlu bir şekilde kullanmayı müzikle gerçekleştirmiştir. Sacks'ın örneğinden hareketle ritim ve senkronizasyonun benzer bir yapılanma içinde olduğu söylenebilir: Ritim, tıpkı bir deniz dalgası ya da kalp atımları gibi düzenli şekilde tekrar eden, eşit şekilde ilerleyen ve metrik bir yapıya sahip olan bir kavramdır (Fraisse, 1982). Senkronizasyon ise, canlıların basit ya da karmaşı bir ritme göre motor becerilerini düzenlemesi ve bir arada hareket etmesi olarak nitelendirilebilir (Atzil ve Gendron, 2017; Semin ve Cacioppo, 2008; Repp, 2005).

Duyuşsal ya da ritmik senkronize olma, içinde hareket barındırmasından ötürü farkındalığa bağlı bir niyetle yapılmaktadır. Bireyler senkronik hareketlenme için başlarda niyete bağlı olmadan hareket edebilirler; daha sonra dikkatin eklenmesiyle bilinçli senkronizasyon oluşur (Repp, 2005). Buradan hareketle, canlı türleri içerisinde insanların, senkronik hareketler geliştirmesinde ortak bir niyetlilikten yararlandıkları görülmektedir. Tomasello da (2008) insanların senkronik hareketler sergilemesinde diğer canlı türlerinden farklı bir amaç 
benimsediğini dile getirir. İnsanın iletişim kurmasında ortak bir niyetliliğin ön planda olduğunu ve "biz" kavramının insanlar açısından önemini vurgular. Ortak niyete bağlı oluşan bu senkronizasyon, insanların sosyal hayatlarının da zeminini yapılandırır; aynı düşünce ve duyguların paylaşılmasıyla birlikte hareketler de benzer şekilde ilerler. Son 15 yıl içerisinde yapılmış birtakım çalışmalarda, ortak niyet ve ritim senkronizasyonu arasında anlamlı bir ilişkinin varlığından söz edilebilir (Kirschner ve Tomasello, 2009; 2010; Stupacher, Maes, Witte ve Wood, 2017).

Tüm bu bilgilerden yola çıkarak bu çalışmada amaçlanan, okul öncesi dönemindeki çocukların senkronize hareketler geliştirmesinde müziğe ait duygusal ipuçlarının ve yüz ifadelerinin uyumunun etkisini incelemektir. Çalışmada 60 - 71 aylık çocukların senkronik davranışlarında bilişsel esneklik faktörü ise kontrol altında tutulmuştur.

Araştırmanın hipotezleri ise şu şekildedir:

Denekler arası yapılacak analizler sonunda, uyumlu koşulda performans sergileyen katılımcıların senkronizasyon puanları ile, uyumsuz koşulda performans sergileyen katılımcıların arasında anlamlı bir fark bulunacaktır. Uyumluluk grubundan beklenen toplam senkronizasyon performansı, uyumsuzluk grubuna göre anlamlı derecede daha yüksek olacaktır. Uyumluluk grubundan beklenen mutlu ve nötr senkronizasyon performans1, uyumsuzluk grubuna göre anlamlı derecede daha yüksek olacaktır.

Koşullarda bağımsız olarak tüm gruplarda, denek içinde iki duygu durumunu içeren (mutlu ve nötr) oturumlara dair senkronizasyon performansları arasında anlamlı bir fark olmayacaktır. Duygu durumunun türü fark etmeksizin, değişkenlerin uyumlu olması durumu senkronizasyonu olumlu yönde etkileyecektir.

\section{YÖNTEM}

Bu bölümde araştırmanın modeli, çalışma grubu, veri toplama araçları ve veri analizine ait bilgiler verilmiştir.

\section{Araştırmanın Modeli}

$\mathrm{Bu}$ araştırmada beş yaşındaki çocukların ritim senkronizasyonlarını sağlamalarında müziğin ve mimiğin etkisini incelemeyi amaçlamıştır; dolayısıyla araştırma yarı deneysel bir yöntemle gerçekleştirilmiştir. Yarı deneysel araştırma, önceden birtakım elemelerden geçerek katılımcı gruplarının oluşmasıyla yürütülen araştırmalardır; deneysel desenden farklı olarak çevredeki tüm olguların kontrolü üzerine odaklanılmamaktadır. $\mathrm{Bu}$ araştırmada da karıştırıcı değişkenlerin deneyin seyrini etkilememesi amacıyla katılımcı seçimleri yapılmıştır. Araştırmada bu kapsamda dört grup üzerinden model oluşturulmuştur (bkz. Tablo 1).

\section{Çalışma Grubu-Evren Örneklem}

Bu çalışma, İstanbul'da yaşayan ve Millî Eğitim Bakanlığı'na bağlı okul öncesi eğitim kurumlarındaki 96 gönüllü öğrenci (48’i kız) ile yürütülmüştür. Katılımcı seçimi yapılırken, çocukların beş yaşını (60 ile 71 aylık arasında) doldurmaları, okul öncesi eğitim kurumlarında eğitim almaları, işitsel veya motor becerilerinde bir problem olmaması ve müzik eğitimini profesyonel şekilde almamaları koşulları aranmıştır. Bilişsel esnekliğin çalışmada önemli bir faktör olabileceği düşünülmüştür; bilindiği gibi bilişsel esnekliğin dört yaşından sonra geliştiği ve sabitlendiği için (Darby ve ark., 2018) araştırma beş yaşındaki çocuklar ile sınırlandırılmıştır. Bu koşulları sağlayan 128 çocuğun ailesinden gerekli izinler alınmıştır; 
ancak bilişsel esneklik puanlanmasında normal dağılıma göre uç değerde puan alan çocuklar $(\mathrm{n}=32)$ çalışmaya eklenmemiştir.

Tablo 1. Gruplara Göre Katılımcı Sayısı Dağılımı ve BADO Puanlarının Ortalama ve Standart Sapma Değerleri

\begin{tabular}{|c|c|c|c|c|c|c|}
\hline \multirow[t]{2}{*}{ Gruplar } & \multirow[t]{2}{*}{$\begin{array}{l}\text { Deneysel } \\
\text { Koşullar }\end{array}$} & \multirow[t]{2}{*}{ Araştırma Deseni } & \multicolumn{2}{|c|}{$\begin{array}{c}\text { Katılımcı } \\
\text { Sayısı }\end{array}$} & \multicolumn{2}{|c|}{ BADO } \\
\hline & & & Kız & Erkek & $\mathbf{X}$ & $\mathbf{S S}$ \\
\hline \multirow[t]{2}{*}{ Uyumlu } & Uyumlu-A & $\begin{array}{ll}\text { 1. } & \text { Mutlu Müzik + Mutlu Mimik } \\
\text { 2. } & \text { Nötr Müzik + Nötr Mimik }\end{array}$ & 12 & 12 & 49.8 & 12.8 \\
\hline & Uyumlu-B & $\begin{array}{ll}\text { 1. } & \text { Nötr Müzik + Nötr Mimik } \\
\text { 2. } & \text { Mutlu Müzik + Mutlu Mimik }\end{array}$ & 12 & 12 & 49.7 & 10.6 \\
\hline \multirow[t]{2}{*}{ Uyumsuz } & Uyumsuz-A & $\begin{array}{l}\text { 1. Nötr Müzik + Mutlu Mimik } \\
\text { 2. Mutlu Müzik + Nötr Mimik }\end{array}$ & 11 & 13 & 51.1 & 7.51 \\
\hline & Uyumsuz-B & $\begin{array}{l}\text { 1. Mutlu Müzik + Nötr Mimik } \\
\text { 2. Nötr Müzik + Mutlu Mimik }\end{array}$ & 12 & 12 & 50.3 & 10.3 \\
\hline
\end{tabular}

Not. BADO: Baş-Ayak Parmakları-Dizler-Omuzlar Görevi

Araştırmada yer alan katılımcıların cinsiyetleri ve deneysel koşullara göre BADO puanlarının ortalama ve standart sapma değerleri Tablo 1'de belirtilmiştir. Deneysel gruplardaki BADO puanları arasındaki farkların analizi tek yönlü Varyans Analizi (ANOVA) ile yapılmıştır. Denekler arası analizde BADO puanları açısından anlamlı bir fark olmadığı tespit edilmiştir $[\mathrm{F}(3,95)=.09, p>.05]$.

\section{Ölçme Araçları}

\section{Demografik Bilgi Formu}

Araştırmacı tarafından oluşturulan ve çocukların aile bireyleri tarafından yanıtlanan form, iki bölümden oluşmaktadır. İlk bölümde ailenin onayı alınırken, ikinci bölümde ise katılımcının müzikle ilgili herhangi bir geçmişi olup olmadığı, işitsel veya alerjik hastalıklarına dair sorular yer almaktadir.

\section{Baş- Ayak Parmakları - Dizler- Omuzlar Görevi (BADO)}

Araştırmanın kontrol değişkeni olan bilişsel esnekliğin değerlendirilmesi için, Baş - Ayak Parmakları - Dizler - Omuzlar Görevinden (BADO) yararlanılmıştır. Bu görev, CameronPonitz, McClelland, Matthews ve Morrison (2009) tarafından geliştirilmiş olup, 4 ile 8 yaş arasındaki çocuklara uygulanmaktadır. Bu oyun serisi üç bölümden oluşmaktadır; her bölüm için eğitim, alıştırma ve test aşamaları vardır. Üç bölümde, bilişsel esnekliğin beden hareketleriyle ölçülmesi için çeşitli komutlar verilir ve bölümler ilerledikçe komutlar ve buna bağlı olarak davranışsal düzenleme zorlaşmaktadır. Görevin uygulanması için araştırmacıdan eğitim ve uygulayıcı e-sertifikası alınmıştır. Görevde en düşük puan 0, en yüksek puan ise 60'dır; bilişsel esneklik ve kendini düzenlemenin yüksek olması yüksek puanla eşleşmektedir. Bu araştırmada olası bir taban etkisinin önüne geçmek için alıştırma bölümünden alınan puanlar da analize dâhil edilmiştir. Bu durumda katılımcılar görevden en düşük 0, en yüksek 94 puan almıştır. 


\section{Müzikli Senkronizasyon Görevi (MSG)}

Katılımcıların ritim senkronizasyonu performanslarını ölçmek ve bağımlı değişkeni incelemek için araştırmacı tarafindan Müzikli Senkronizasyon Görevi (MSG) geliştirilmiştir. Bu görevde katılımcılar, belirlenmiş olan müzik ve mimiklere göre ritmik senkronizasyon performansı gerçekleştirmişlerdir.

Şekil 1'de görüleceği üzere, MSG için geliştirilen düzenek ve seçilen ekipman, ritmin kaydedilmesi ve analiz edilmesi için özel olarak seçilmiştir; bu konuda müzisyenler ve diğer uzmanlardan görüşler alınmıştır. Ritmin hem çocuk hem de karakter tarafından çalınabilmesi için bir bongo kullanılmıştır. Masif ağaçtan yapılan "Mini Extreme XB1013GR" bongo modelinin iki yuvarlak kısmı bulunmaktadır; büyük kısmın çapı $13 \mathrm{~cm}$, küçük kısmın çapı ise $10 \mathrm{~cm}$ 'dir. Ritimlere ait ses dalgalarının kaydolması için taşınabilir ses kayıt cihazlarından biri olan "Zoom H5" kullanılmıştır. Videonun izlenmesi ve videoya ait sesin, katılımcının ritmiyle çıkacak sese karışmaması amacıyla çocukların takacağı bir adet küçük boy kulak üstü kulaklık (SONY MDR-ZX310W) kullanılmıştır. Videolar, 13" ekranlı bir bilgisayar yardımıyla katılımcılara gösterilmiştir.

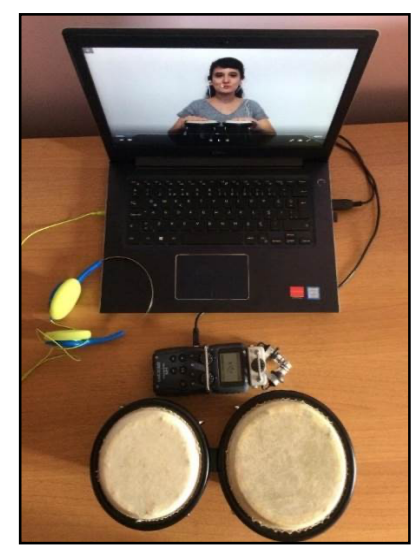

Şekil 1. Ekipman Düzeni

Videolar öncesinde ritme dair deneme videosu izletilir ve katılımcının takip ederek bongoya alışması beklenir. Deneme videosunda gerektiği takdirde geri bildirimler verildikten sonra koşulları içeren asıl videolara geçilir ve bu aşamalarda herhangi bir geri bildirim verilmez. Her bir videodan en düşük 0, en yüksek 14 puan alınır; iki video üzerinden bir katılımcı maksimum 28 puan alabilmektedir. Puanın yüksekliği, yüksek senkronizasyon seviyesini göstermektedir.

\section{Görevin Geliştirilmesi ve Pilot Uygulamaları}

Videoların oluşum sürecinde ilk olarak kullanılacak müzikler belirlenmiştir. Çocuklar ve yetişkinlerle yapılan araştırma sonucunda mutlu müzik için en yüksek puanı alan parça Vince Guaraldi Trio'nun “Linus ve Lucy” olmuştur. Parçanın özellikleri şu şekildedir: genel olarak majör akorlardan oluşmaktadır, 160 BPM'lik ritme sahiptir, bir liriği yoktur, sadece ritim ve piyanodan oluşmaktadır, dört dörtlük tempodadır. Araştırmada parçanın sadece piyanolu olan ilk bir dakikası kullanılmıştır. Likert ölçümü sonucunda ortalama bir puan alan nötr müzik ise, yine dört dörtlük bir eser olarak seçilmiş, Claude Debussy'nin La Mer adlı eserinin 3. Bölümü "Dialogue du vent et de la mer (Rüzgar ve denizin diyalogu)" adlı kısmıdır. Söz konusu eserin 
piyano transpoze kaydı kullanılmıştır. 82 BPM'lik bu parçanın, sabit ritimli olan kısmı çalışmada kullanılmak üzere değerlendirilmiştir.

Videolarda mimiklerin tam olarak ifade edilmesi için tiyatroda eğitim almış bir sanatçı ile çalışılmıştır. Ekipman kurulumu, katılımcının çalması gerektiği biçimde düzenlenmiştir. Sanatçı videonun başında oturur pozisyondadır ve elleri bongonun üzerinde olacak şekilde ekrana bakmaktadır. Kendisini tanıtmasının ardından sabit ritmi çalmaya başlar ve aynı anda yüz ifadelerini koşula göre oluşturur. Çalışma için seçilen mimikler mutlu ve nötr yüz ifadeleri olarak belirlenmiştir (bkz. Şekil 2). Video başlangıcında sanatçı kendini tanıtmak için birkaç cümle kurmaktadır.
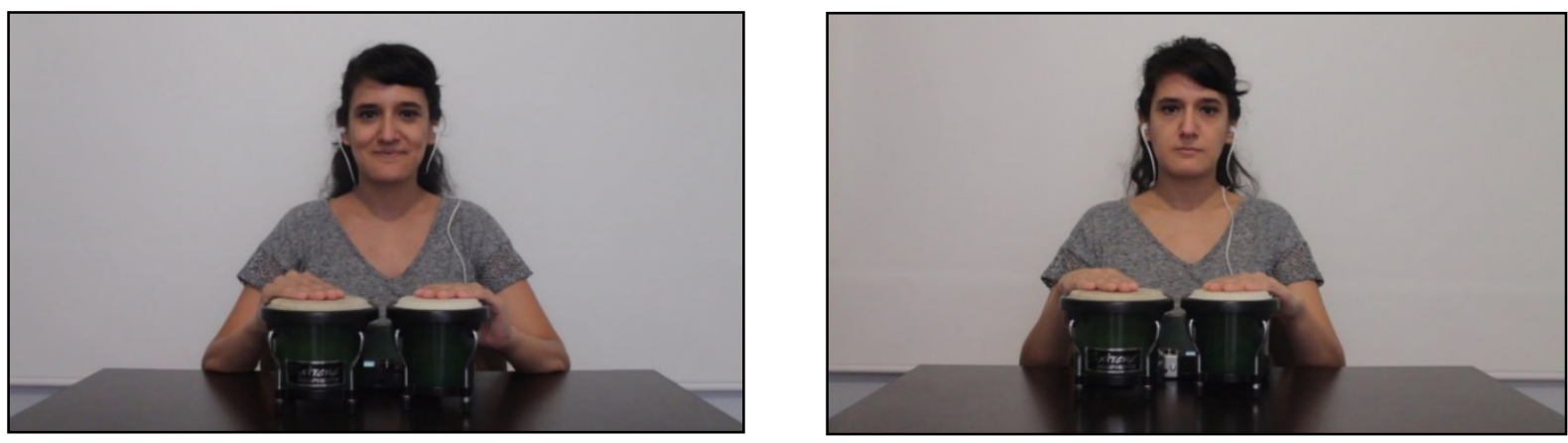

Şekil 2. Karakterin Mutlu ve Nötr Yüz İfadesi Gösterimi

Tanıtım kısmı yaklaşık on saniye sürmektedir. Ardından sanatçı 80 BPM hızdaki ritmi sabit bir şekilde çalmaya başlar. Sanatçı, sağ ve sol ellerini birer defa kullanarak basit bir dört dörtlük ritmi çalmıştır ve katılımıının da bu ritmi yapmasını istemiştir.

Videoların kurgulanmasının ardından, bilişsel gelişim psikolojisi alanında çalışan bir grup yüksek lisans ve doktora öğrencisi ile bir öğretim üyesine videolar ve yönergeler sunulmuştur. $\mathrm{Bu}$ bağlamda uygulama etiği hakkında fikirler değerlendirilmiştir ve yönergeler oluşturulmuştur. Yönergelerin çocuklara olan uygunluğunun test edilmesi için İstanbul'da bir anaokulunda pilot çalışmalar yapılmıştır. Her koşul için bir kişinin fikri incelenmiştir. Uygulamalar video kaydına alınmıştır ve kayıtların incelenmesinin sonucunda deneysel yönergelerin araştırmacı, karakter ve katılımcı arasındaki iş birliğini sağladığı belirlenmiştir.

\section{Verilerin Toplanması ve Analiz}

Araştırmada her türlü gürültünün olmamasına dikkat edilmiştir ve bu kapsamda sessiz, dikkat dağıtmayan ortamlarda ses kayıtları alınmıştır. Ekipman kurulumu gerçekleştikten sonra gönüllüler teker teker oyun alanına davet edilmiştir ve araştırmacı, deney boyunca katılımcının yanında durmuştur. Koşullara göre her uygulamada duygu durumlarının dengelenmesi sağlanmıştır. Katılımcılar bilgisayarın karşısına oturtulmuştur ve adından tüm ekipmanın tanıtımı yapılmıştır. Katılımcıların ortama ve ekipmana alışması için bir süre verilmiştir.

Katılımcının alışma süresinden sonra, "Şimdi seninle müzikli bir oyun oynayacağız. Bilgisayarda görmüş olduğun bu abla bir müzik yapıyor, senden de ricam ablayı dikkatli bir şekilde izlemen ve onun çalmış olduğu ritmin aynısını çalman. Kısacası, birlikte müzik yapacaksınız. Hazır mısın?" diye sorularak çalışmaya davet edilmiştir. Kulaklıkları takmasının ardından video uygulamalarına başlanmıştır. Araştırmacı bu aşamada "Sana şimdi örnek bir video göstereceğim," demiştir ve hazırlanan videolardan öncelikle müziksiz olanı 
gösterilmiştir. Araştırmacı bu esnada olası bir hatada (katılımcının konuşması veya başka sesler çıkarması gibi) katılımcıya gerekli geri bildirimler yapmıştır.

Daha sonra araştırmacı, "Hazırsan asıl videolara geçiyoruz," komutuyla katılımcıları deney aşamasına yönlendirmiştir ve koşullara göre hazırlanan videolar gösterilmeye başlanmıştır. Katılımc1 da önündeki bongoyla, videodaki karakterin çaldığ 1 ritmi takip etmiştir. Bu sırada katılımcının çaldığ bildirimde bulunmamıştır.

Hazırlanan iki video arasına ritmin öğrenilmemesi ve bilişsel esnekliğin ölçümü için BADO görevi eklenmiştir. Tüm çalışma her bir katılımcı için ortalama 15 dakika sürmektedir; iki video için ortalama 3-4 dakika, BADO görevi için 7-8 dakika, alışma süreci için ise 2-3 dakikalık zaman dilimi ayrılmıştır. Tüm gruplara aynı yönerge uygulanmıştır.

Müziğin ve mimiğin, çocukların senkronik performanslarına olan etkilerinin neler olduğunu anlamlandırmak için yapılan analizler, özellikle tempoya uyum üzerinden ilerlemiştir. Öncelikle katılımcıların ritmi vurmaları gereken anda görevi gerçekleştirmeleri incelenmiştir. Buradan genel bir senkronizasyon ölçümü yapılmıştır. Ortalama olarak bir dakikalık ses kayıtları 14 eş parçaya bölündükten sonra, videodaki karakterin çaldığı kayıt ile arasındaki Pearson korelasyona bakılmıştır. Korelasyonla amaçlanan, katılımcı ile karakterin ritmi çaldığı zamandaki zirve noktalarının zamansal yakınlığını bulmaktır. 14 eş birime bölünmesinin sebebi, katılımcıların sağ ve sol ellerindeki ritmi vurma süresinin yaklaşık olarak 4.5 saniyeye denk gelmesidir; 64 saniyelik ses kayıtlarında 14 adet birim katılımcıların sağ ve sol hareketi tek seferde yaptığı bu 4.5 saniye üzerinden belirlenmiştir. Zaman serilerinden elde edilen ve anlamlı olan toplam korelasyon parçaları üzerinden bir puanlama sistemi geliştirilmiştir. Tüm katılımcıların gerçekleştirebileceği maksimum anlamlı korelasyon puanı, iki koşul toplamı için 28 olarak saptanmıştır.

Katılımcıların deney koşullardaki ses kayıtları üzerinden elde edilen, toplam korelasyon sayısına bağlı puanlamalar arasındaki farklar, tek yönlü Varyans Analizi (ANOVA) ve Bağımlı T-test ile değerlendirilmiş, deneysel grupların ortalamaları arasındaki farklar değerlendirilirken de Tukey's Honestly Significant Difference (HSD) Post-hoc Testi kullanılmıştır. Basıklık ve çarpıklık değerlerine göre katılımcıların normal dağıldığı görülmüştür. Deney gruplarının denek içi farklarının incelenmesi için de Bağımlı T-Test analizleri yapılmıştır. Denekler arası parçalı korelasyon analizleri için MatLab, yine denekler arası varyans analizleri için ise SPSS 21 programları kullanılmıştır.

\section{BULGULAR VE TARTIŞMA}

$\mathrm{Bu}$ araştırmanın amacı, okul öncesi dönemindeki çocukların ritim senkronizasyonlarını sağlamalarında duygusal ipuçları olarak mimiğin ve müziğin etkisini incelemektir. Bu amaçla yapılan uyumlu ve uyumsuz deney gruplarına ait senkronizasyon puanları oturumlara göre karşılaştırılmıştır. Gruplara göre deneysel koşulların senkronizasyon puanlarının ortalaması ve standart sapma değerleri toplu olarak Tablo 2'de gösterilmiştir. 
Tablo 2. Deneysel Koşulların Senkronizasyon Puanlarının Ortalama ve Standart Sapma Değerleri

\begin{tabular}{|c|c|c|c|c|c|c|c|c|c|c|c|c|}
\hline & \multicolumn{6}{|c|}{ Uyumlu } & \multicolumn{6}{|c|}{ Uyumsuz } \\
\hline & \multicolumn{3}{|c|}{ Uyumlu - A } & \multicolumn{3}{|c|}{ Uyumlu-B } & \multicolumn{3}{|c|}{ Uyumsuz - A } & \multicolumn{3}{|c|}{ Uyumsuz - B } \\
\hline & $\mathrm{n}$ & $X$ & SS & $\mathrm{n}$ & $X$ & SS & $\mathrm{n}$ & $X$ & SS & $\mathrm{n}$ & $X$ & SS \\
\hline Mutlu Senk. ${ }^{a}$ & 24 & 3.83 & 1.76 & 24 & 3.45 & 2.20 & 24 & 1.25 & 1.48 & 24 & 1.29 & 1.33 \\
\hline Nötr Senk. & 24 & 3.58 & 2.14 & 24 & 3.41 & 1.99 & 24 & 1.91 & 1.61 & 24 & 1.66 & 1.57 \\
\hline Toplam Senk. ${ }^{c}$ & 24 & 7.41 & 2.08 & 24 & 6.87 & 3.37 & 24 & 3.16 & 1.94 & 24 & 2.95 & 2.11 \\
\hline $\begin{array}{l}p<05 \\
a . \text { Mutlu Senk.: } \\
b . \text { Nötr Senk.: } \\
\text { c. Toplam Senk }\end{array}$ & $\mathbf{r S}$ & $\begin{array}{l}\text { ron } \\
\mathrm{Se}\end{array}$ & yon & ler & & & & & & & & \\
\hline
\end{tabular}

Araştırmanın senkronizasyon puanlamasına ilişkin hipotezlerini incelemek üzere, deney koşullarına ait değiş̧kenler üzerinden ANOVA uygulanmıştır. ANOVA sonuçlarına göre, koşullar arasındaki toplam senkronizasyon puanlarında anlamlı fark olduğu tespit edilmiştir $[F(3,95)=22.426, p<.001]$. Tukey HSD Post-hoc analizine göre, Uyumlu - A ve Uyumsuz - A ortalamaları ile Uyumlu A ve Uyumsuz $-\mathrm{B}$ arasındaki farklar anlamlıdır $(p<.001)$. Ayrica Uyumlu - B ve Uyumsuz - A ortalamaları ile Uyumlu - B ve Uyumsuz B ortalamaları arasındaki farklar da anlamlıdır $(\mathrm{p}<.001)$. Uyumlu grupların kendi içlerinde anlamlı fark bulunamadığı gibi $(p=.87)$, uyumsuz grupların ortalama puanlarında da herhangi bir anlamlı fark tespit edilmemiştir $(p=.99)$.

Araştırmanın mutlu ve nötr senkronizasyon puanlamasına ilişkin alt hipotezlerini incelemek amacıyla, deney koşullarına ait değişkenler üzerinden ANOVA uygulanmıştır. ANOVA sonuçlarına göre, koşullar arasındaki toplam senkronizasyon puanlarında anlamlı fark olduğu görülmüştür [sırasıyla $\mathrm{F}(3,95)=15.301, p<.001$ ve $\mathrm{F}(3,95)=6.92, p<.001$ ].

Mutlu senkronizasyon puanları için yapılan Tukey HSD Post-hoc analizine göre, Uyumlu - A ve Uyumsuz - A ortalamaları ile Uyumlu A ve Uyumsuz - B arasındaki farklar anlamlıdır $(\mathrm{p}<.001)$. Ek olarak, Uyumlu - B ve Uyumsuz - A ortalamaları ile Uyumlu - B ve Uyumsuz B ortalamaları arasındaki farklar da anlamlıdır $(p<.001)$. Uyumlu grupların kendi içlerinde anlamlı fark bulunamadığı gibi $(p=.80)$ uyumsuz grupların ortalama puanlarında da herhangi bir anlamlı fark saptanmamıştır $(p=.99)$.

Nötr senkronizasyon puanları için yapılan Tukey HSD Post-hoc analizine göre, Uyumlu - A ve Uyumsuz - A ortalamaları ile Uyumlu A ve Uyumsuz - B arasındaki farklar anlamlıdır $(p<.05)$. Ek olarak, Uyumlu - B ve Uyumsuz - A ortalamaları ile Uyumlu - B ve Uyumsuz B ortalamaları arasındaki farklar da anlamlıdır $(\mathrm{p}<.05)$. Uyumlu grupların kendi içlerinde anlamlı fark bulunamadığ 1 gibi $(p=.99)$, uyumsuz grupların ortalama puanlarında da herhangi bir anlamlı fark tespit edilmemiştir $(p=.91)$.

Araştırmanın son hipotezinde, uyumlu veya uyumsuz koşullardan bağımsız olarak, duygu durumları türlerinin (mutlu ve nötr) gruplar içerisinde senkronizasyon puanlaması açısından bir fark yaratıp yaratmadığı bağımlı örneklem t-test ile incelenmiştir. Tablo 2'deki ortalamalara 
tekrar odaklanıldığında, koşullardan bağımsız olarak duygu durumlarının türünün senkronize olmada anlamlı bir fark yaratmadığ 1 bulunmuştur.

Yapılan denek içi analiz sonuçlarına göre Uyumlu - A grubunun mutlu ve nötr senkronizasyon puanları arasında anlamlı bir fark bulunamamıştır $(\mathrm{t}(23)=.37, p=.71)$. Uyumlu $-\mathrm{B}$ grubu için de benzer sonuçlar elde edilmiştir; denek içi analizi sonucunda anlamlı farka ulaşılamamıştır $(\mathrm{t}(23)=-1.35, p=.18)$. Uyumsuz gruplar içinde ise senkronizasyon performansları arasında anlamlı farklar elde edilememiştir (sırasıyla Uyumsuz - A için $\mathrm{t}(23)=-.80, p=.92$; Uyumsuz $\mathrm{B}$ için $\mathrm{t}(23)=-.91, p=.38$ ). Buradan hareketle, senkronizasyonu etkileyen mimik ve müziğe ait duygu durumlarının türü yerine, birbirleriyle olan uyumunun senkronizasyon performansları üzerinde olumlu etkisi olduğu görülmektedir.

Araştırmalara göre, insanların ritim senkronizasyonunu gerçekleştirirken yapmış oldukları öngörülü hataların azaltılmasında iki önemli nedenden söz edilebilir. İlk olarak, bireye gönderilen ritim uyaranıyla birlikte, farklı bir bildirim ya da uyarıcı gönderilmesidir. İkincisi ise, somatosensoriyel bildirimlerin daha güçlü vuruşlar yaptırılarak yoğunlaştırılması şeklinde olmaktadır (Aschersleben, 2002; Krause, Pollok ve Schnitzler, 2010; Repp, 2005). Buradan hareketle, ritim senkronizasyonunda hata paylarının düşürülmesi için, katılımcılara takviye olarak birtakım uyarıcılar, örneğin mimik gibi sözel olmayan duygusal ip uçlar, gönderilebilir. Veya, parmakların veya ellerin daha yukarıdan hareket ettirilmesiyle oluşan kinestetik bildirim, senkronizasyonun artmasını sağlayabilir. Bu araştırmada da sözü edilen iki unsurun birleşimi üzerinden hipotezleri destekler nitelikte sonuçlar elde edilmiştir. Mimiklerin ve müziklerin duygusal ipuçlarının birlikteliği sayesinde katılımcıların senkronize olmalarındaki hatalar düşürülmüş̧ür. Ayrıca uyuma dair ipuçların hem görsel hem de işitsel olarak verilmesi sayesinde senkronizasyon performansının olumlu yönde etkilendiği gözlemlenmiştir.

Araştırmadaki bulgulardan birisi, duygu durumunun türünden bağımsız olarak senkronizasyonun gerçekleşmesinde duygu durumlarına dair ipuçlarının uyumunun etkisinin bulunmasıdır. Literatürde müziğin duygu durumu çeşitlerinin senkronize olma üzerindeki etkisiyle ilgili az sayıda çalışma vardır. Bu çalışmada ise, müzik ile birlikte mimiğin var olmasıyla oluşturulan, yeni bir model değerlendirilmiştir ve sonuçlara göre çeşitliliğin fark etmediği görülmüştür. Bu açıdan değerlendirildiğinde, görsel ve işitsel bildirimlerin bu alandaki çalışmaların seyrini etkileyebileceği dile getirilebilir. Nitekim Patel ve arkadaşları (2005), yapmış oldukları çalışmada her bir katılımcının hem görsel hem de işitsel ritim görevlerini gerçekleştirmelerini beklemiştir. Sonuçta, bireylerin işitsel ritim sayesinde, görsel ritme göre daha başarılı senkronizasyon geliştirdiklerini gözlemlemişlerdir. Bu çalışma ise Patel ve arkadaşlarının (2005) yapmış olduğu araştırmanın bir ileri boyutu olarak düşünülebilir; negatif asenkronizasyonların azaltılmasında hem görsel (mimik ve video gösterimi) hem de işitsel (müzik) ipuçlarının etkisinden söz etmek mümkündür.

\section{SONUÇ VE ÖNERILER}

$\mathrm{Bu}$ araştırmada, beş yaşındaki çocukların ritim senkronizasyonlarını sağlamalarında müzik ve mimik eşleştirilmesinin etkisi incelenmiştir. Bu kapsamda özel bir görev geliştirilmiştir ve çocuklarda uygulamasının yapılması için birtakım ön çalışmalar sunulmuştur. Ardından çalışma yürürlüğe konulmuş ve hipotezler değerlendirilmiştir. Araştırmanın sonuçlarına göre:

1. MSG ile uyumlu koşulda yer alan katılımcılar ile uyumsuz koşulda yer alan katılımcıların senkronizasyon puanları arasında anlamlı derecede bir fark bulunmuştur. Buna göre uyumlu grubu, yani müziğin duygu durumu ile yüz ifadeleri arasındaki 
uyumla değerlendirilen grup, genel anlamda senkronize olmada daha başarılı olmuştur. Uyumlu koşulda yer alan katılımcılar hem mutlu hem de nötr senkronizasyon puanlamasında daha yüksek skorları elde etmişlerdir. Bu bağlamda uyumluluk grubunun senkronizasyon performansı, uyumsuzluk grubuna göre anlamlı derecede daha fazladir.

2. Uyumlu ve uyumsuz gruplarda, grup içinde iki duygu durumunu içeren (mutlu ve nötr) oturumlarına dair senkronizasyon performansları arasında anlamlı bir fark bulunmamıştır. Koşullardan bağımsız olarak, grupların kendi içlerindeki senkronizasyon performanslarında asıl etkili olanın, duygu durumu türü fark etmeksizin mimik ve müzik ipuçlarının uyumlu olmasıdır.

Müzikli Senkronizasyon Görevi (MSG), çocukların ritim senkronizasyonlarının ölçülmesinde karşılarında görmüş oldukları karakterle ortak bir niyete bağlı oynanan, müziğin ve mimiğin duygusal ipuçlarına uyumuna dikkat çeken, bedenlenmiş biliş kavramı üzerinden geliştirilen bir görevdir. Müzik ve mimik eşleşmelerinin katılımcıların senkronizasyonu üzerindeki etkilerinin değerlendirildiği bu çalışmadan çıkarılan sonuçlar, hipotezleri destekler niteliktedir.

$\mathrm{Bu}$ çalışma ile yarı deneysel bir ortamda müziğin ve mimiğin, algılama sürecindeki etkileri hakkında fikir sahibi olunmuştur. Özellikle eğitim kurumlarında duygu üzerine yapılacak çalışmalarda, okul öncesi dönemindeki çocukların duyguları anlamlandırabilmeleri açısından müziği de bir araç olarak kullanabilecekleri söylenebilir. Pilot ve esas çalışmada yer alan çocukların duyguları anlamlandırma ve dile getirmede farklılıklar tespit edilmiştir. Söz konusu farklılığın ortaya çıkmasında da müziğin duygusal yapısından söz edilebilir.

İleriki araştırmalar için, farklı yaş grupları ile bu oyunun tekrarlanması sağlanabilir. Bilişsel esnekliğe ek olarak farklı değişkenlerin de ekleneceği bir çalışma gerçekleştirilebilir. Parçalı korelasyon ve senkronizasyon analizlerinin sonuçlarıyla ortaya çıkan yukarıdaki tartışmalar, ileriki çalışmalarda tekrar incelenebilir.

$\mathrm{Bu}$ araştırmanın sonuçlarıyla birlikte, bedenleşmiş biliş ve ortak niyet kavramları üzerinden oluşturulan senkronizasyon görevlerinde müziğe ait duygu durumlarının ve yüz ifadeleriyle gelen ipuçların uyumunun, senkronizasyon performansı üzerinde anlamlı derecede olumlu etkisi olduğu hipotezi desteklemiştir. Bunun yanında, bilişsel esnekliğin de kontrol edilmesiyle birlikte senkronize olmadaki etkisi sabitlenmiş ve oturumlar arasında herhangi bir fark yaratmadığı da saptanmıştır. Bu bilgiler ışığında, okul öncesi dönemindeki çocukların ritim senkronizasyonlarını sağlamalarında dikkat becerileri kontrol altındayken, verilmiş olan ipuçların uyumunun etkisi olduğu dile getirilmiştir. 


\section{KAYNAKÇA}

Atzil, S. \& Gendron, M. (2017). Bio-behavioral synchrony promotes the development of conceptualized emotions. COPSYC, 17, $162-69$. DOI: 10.1016/j.copsyc.2017.07.009.

Aschersleben, G. (2002). Temporal control of movements in sensorimotor synchronization. Brain and Cognition, 48, 66-79. DOI: 10.1006/brcg.2001.1304.

Cameron-Ponitz, C. E., McClelland, M. M., Matthews, J.S. \& Morrison, F. (2009). A structured observation of behavioral self-regulation and its contribution to kindergarten outcomes. Developmental Psychology, 45, 605-619. DOI: 10.1037/a0015365.

Darby, K. P., Castro, L., Wasserman, E. A. \& Sloutsky, V. M. (2018). Cognitive flexibility and memory in pigeons, human children, and adults, Cognition, 177, 30-40. DOI: 10.1016/j.cognition.

Fraisse, P. (1982). Rhythm and tempo. D. Deutsch (Ed.), The Psychology of Music içinde (pp. 149 - 180). New York: Academic Press.

Juslin, P. N. \& Sloboda, J. A. (2011). Music and Emotion. P. Juslin and J. Sloboda (Ed.), Handbook of Music and Emotion: Theory, Research, Applications içinde (pp.583 645). United Kingdom: OUP Oxford.

Kischner, S. \& Tomasello, M. (2010). Joint drumming: social context facilitates synchronization in preschool children. Journal of Experimental Child Psychology, 102, 299 - 314. DOI: 10.1016/j.jecp.2008.07.005.

Kischner, S. \& Tomasello, M. (2009). Joint making music promotes pro-social behavior in 4year-old children. Evolution and Human Behavior, 31, 354 - 364. DOI: 10.1016/j.evolhumbehav.2010.04.004.

Krause, V., Pollok, B. \& Schnitzler, A. (2010). Perception in action: the impact of sensory information sensorimotor synchronization in musicians and non-musicians. Acta Psychologica, 133, 28 - 37. DOI: 10.1016/j.actpsy.2009.08.003.

Leman, M. \& Maes, P. (2014). Music perception and embodied music cognition. L. Shaphiro (Ed.), The Routledge Handbook Of Embodied Cognition içinde (pp. 81 - 89). New York: Routledge.

Niendental, P. (2007). Embodying emotion. Science, 316, 1002 - 1005. DOI: 10.1126/science. 1136930 .

Patel, A. D., Iversen, J. R., Chen, Y. \& Repp, B. (2005). The influence of metricality and modality of syncronization with a beat. Experimental Brain Research, 163, 226 - 238. DOI: $10.1007 / \mathrm{s} 00221-004-2159-8$.

Repp, B. H. (2005). Sensorimotor synchronization: a review of the tapping literature. Psychonomic Bulletin \& Review, 12(6), 969 - 92. DOI: 10.3758/BF03206433.

Sacks, O. (2008). Musicophilia - tales of music and the brain. New York: Vintage Books.

Semin, G. R. \& Cacioppo, J. T. (2008). Grounding Social Cognition: Synchronization, Entrainment, and Coordination. G. R. Semin \& J.T. Cacioppo (Ed.), Embodied Grounding: Social, Cognitive, Affective, And Neuroscientific Approaches içinde (pp. 119 - 148). New York: Cambridge University Press.

Stupacher, J., Maes, P., Witte, M. \& Wood, G. (2017). Music strengthens prosocial effects of interpersonal synchronization - if you move in time with the beat. Journal of Experimental Social Psychology, 72, 39 - 44. DOI:10.1016/J.JESP.2017.04.007.

Thelen, E. (2000). Grounded in the world: developmental origins of the embodied mind. Infancy, 1(1), 3 - 28. DOI: 10.1207/s15327078in0101_02.

Tomasello, M. (2008). Origins of human communication. Massachusetts: The MIT Press. 
Wood, A., Rychlowska, M., Korb, S. \& Niendental, P. (2016). Fashioning the Face: Sensorimotor Simulation Contributes to Facial Expression Recognition. Trends in Cognitive Sciences, 20(3), 227 - 40. DOI: 10.1016/j.tics.2015.12.010.

Zhou, Y. \& Fischer, M. H. (2018) Mimicking non-verbal emotional expression and empathy development in simulate consultations: an experimental feasibility. Patient Education and Counseling, 101(2), 1 - 6. DOI: 10.1016/j.pec.2017.08.016. 